\title{
Algoritmo para la navegación autónoma de un vehículo aéreo no tripulado en pasillos de adoquín gris
}

\section{Algorithm for autonomous navigation of an unmanned aerial vehicle in gray cobblestone corridors}

MARTÍNEZ-LUNA, Salvador $\dagger$, SÁNCHEZ-ACEVEDO, Miguel Angel*, MARTINEZ-GIL, Carmen Carlota y MÁRQUEZ-DOMÍNGUEZ, José Alberto

Universidad de la Cañada, Teotitlán de Flores Magón, Oaxaca, México

ID $1^{\text {er }}$ Autor: Salvador, Martínez-Luna / ORC ID: 0000-0002-3978-9876, CVU CONACYT ID: 1009195

ID $1^{\mathrm{er}}$ Coautor: Miguel Angel, Sánchez-Acevedo / ORC ID: 0000-0002-0996-0038, CVU CONACYT ID: 205720

ID $2^{\text {do }}$ Coautor: Carmen Carlota, Martinez-Gil / ORC ID: 0000-0001-6335-8278, CVU CONACYT ID: 97751

ID $3^{\text {er }}$ Coautor: José Alberto, Márquez-Domínguez / ORC ID: 0000-0003-2552-2289, CVU CONACYT ID: 210472

DOI: $10.35429 / J E A .2019 .18 .6 .29 .36$

Recibido: 19 de Enero, 2019; Aceptado 30 de Marzo, 2019

\section{Resumen}

Para que un Vehículo Aéreo no Tripulado (VANT) pueda navegar con una autonomía total se requieren muchos sensores y una alta capacidad de procesamiento. Los VANT con mayor autonomía hoy en día, cuentan con sensores como cámaras estereoscópicas, láser, sensores ultrasónicos, entre otros. Además, es necesario que el VANT cuente con una tarjeta capaz de procesar cada uno de los datos recibidos por los sensores. La desventaja de que haya muchos sensores integrados en un VANT es que incrementan su costo, lo hacen más pesado, consumen mayor energía y reducen el tiempo de vuelo. En este artículo se presenta el diseño e implementación de un algoritmo que permite a un VANT navegar en línea recta de forma autónoma sobre pasillos de adoquín gris libres de obstáculos, utilizando únicamente la cámara integrada. Al VANT se le adaptó un smartphone el cual se encarga de realizar el procesamiento digital de imágenes. Para evaluar el adecuado funcionamiento del VANT se realizaron pruebas sobre pasillos de la Universidad.

Vehículo aéreo no tripulado, Navegación autónoma, Procesamiento digital de imágenes

\begin{abstract}
Several sensors and high processing capacity are required for allowing to an unmanned aerial vehicle (UAV) navigate with total autonomy. The UAVs with greater autonomy have sensors such as stereoscopic cameras, lasers, ultrasonic sensors, among others. In addition, it is necessary that the UAV has a microcontroller capable of processing each of the data received by the sensors. The disadvantage of having many sensors integrated into an UAV is that they increase its cost, make it heavier, consume more energy and reduce flight time. This article presents the design and implementation of an algorithm that allows an UAV to navigate in a straight line in an autonomous way over obstacle-free gray pavements, using only the integrated camera. The VANT was adapted to a smartphone which is responsible for the digital processing of images. To evaluate the proper functioning of the UAV, tests were carried out on corridors at the University.
\end{abstract}

Unmanned aerial vehicle, Autonomous navigation, Digital image processing

Citación: MARTÍNEZ-LUNA, Salvador, SÁNCHEZ-ACEVEDO, Miguel Angel, MARTINEZ-GIL, Carmen Carlota y MÁRQUEZ-DOMÍNGUEZ, José Alberto. Algoritmo para la navegación autónoma de un vehículo aéreo no tripulado en pasillos de adoquín gris. Revista de Aplicaciones de la Ingeniería. 2019. 6-18: 29-36

\footnotetext{
* Correspondencia del Autor (Correo electrónico: masanchez@unca.edu.mx)

$\dagger$ Investigador contribuyendo como primer autor.
} 


\section{Introducción}

Los Vehículos Aéreos No Tripulados (VANT) son vehículos que vuelan sin la necesidad de que haya un piloto dentro de ellos. En un vehículo aéreo normal el piloto es quien controla y ejecuta las maniobras de vuelo; un vehículo autónomo no recibe indicaciones de una persona, sino del algoritmo que lo controla. La aplicación de monitoreo cuenta con un botón de pánico para que el usuario (experto o inexperto) pueda aterrizar el dron inmediatamente en caso de un comportamiento inesperado. El vuelo autónomo se puede lograr a través de sensores tales como radares, láseres, cámaras, o GPS.

Dentro de la categoría de vehículos aéreos no tripulados, existe una gran variedad con respecto a sus tamaños; hay vehículos desde el tamaño de un mosquito hasta vehículos de tamaño real. En los últimos años estos vehículos han sido de mucha ayuda ya que han entrado a zonas peligrosas tales como la planta nuclear Fukushima (Engel, 2011). También han ayudado a localizar personas gracias a que se les pueden adaptar diferentes equipos tales como cámaras de video, sensores de calor, entre otros dispositivos que, en los últimos años, han estado en el ámbito de investigación como también en el ámbito comercial. La mayoría de VANT utilizados en estas tareas son controlados a distancia por una persona capacitada para la tarea a realizar.

Para que un VANT pueda navegar con una autonomía total se requieren muchos sensores y una alta capacidad de procesamiento. Las propuestas que han dotado a los VANT con mayor autonomía hacen uso de cámaras estereoscópicas (Schiaffino, 2006; RiverosGuevara, Salas-López y Solaque-Guzmán, 2012; García, 2016; Navas-Flores y VargasSuasnavas, 2018), sensores tales como radares, láseres, cámaras o GPS (Viñals-Pons, 2012; Araujo-Fernandeza y García-González, 2013; Sarmiento y otros, 2014; Munguía, Cabrera, Rojas y Martínez-Carranza, 2016; MartínezCarranza, Valentín, Márquez-Aquino, González-Islas y Loewen, 2016; Plaza-Rey, 2017), e inteligencia artificial (Fuentes-Brea, 2013; Guevara-Soriano, Reyes-Montero y Sánchez-López, 2017; Hossian y otros, 2018; Monroy, 2018). Además, es necesario que el VANT cuente con una unidad capaz de procesar cada uno de los datos recibidos por los sensores.
La desventaja de que haya muchos sensores integrados en un VANT es que incrementan su costo, lo hacen más pesado, consumen mayor energía y reducen el tiempo de vuelo.

El objetivo de este trabajo es implementar un algoritmo que permita la navegación autónoma de un VANT por adoquín gris a una altura de $1 \mathrm{~m}$ (altura default de despegue) de tal forma que se pueda utilizar solo la cámara integrada del VANT. Para realizar las pruebas del algoritmo se utilizará el cuadrirotor Parrot Bebop 2, un VANT que cumple con las características básicas para este trabajo y se ha elegido por lo económico de su costo. El cuadrirotor Parrot Bebop 2 cuenta con una cámara integrada de 14 megapíxeles la cual se utilizará para la captura de imágenes.

La combinación de diversos métodos de procesamiento digital de imágenes enfocados a la captura de imágenes a través de una cámara, generan un algoritmo eficiente que le permite a un VANT la navegación autónoma sobre pasillos de adoquín gris, ya que se pueden establecer parámetros para detectar líneas rectas en las imágenes capturadas para que de esta forma el VANT pueda navegar sobre los pasillos de adoquín gris de forma correcta.

\section{Procesamiento Digital de Imágenes}

El procesamiento digital de imágenes (PDI) nos permite aplicar procesos aritméticos para extraer características de alguna imagen (Esqueda, 2002). A continuación, se describen las técnicas de procesamiento digital de imágenes que se aplicaron en el presente trabajo.

Con la finalidad de agrupar colores similares dentro de la imagen se utilizó la umbralización (Figura 1). La idea es representar el color de forma redundante y encontrar los parámetros de color para el cual el umbral hace la segmentación deseada (Ballard y Brown, 1982). 


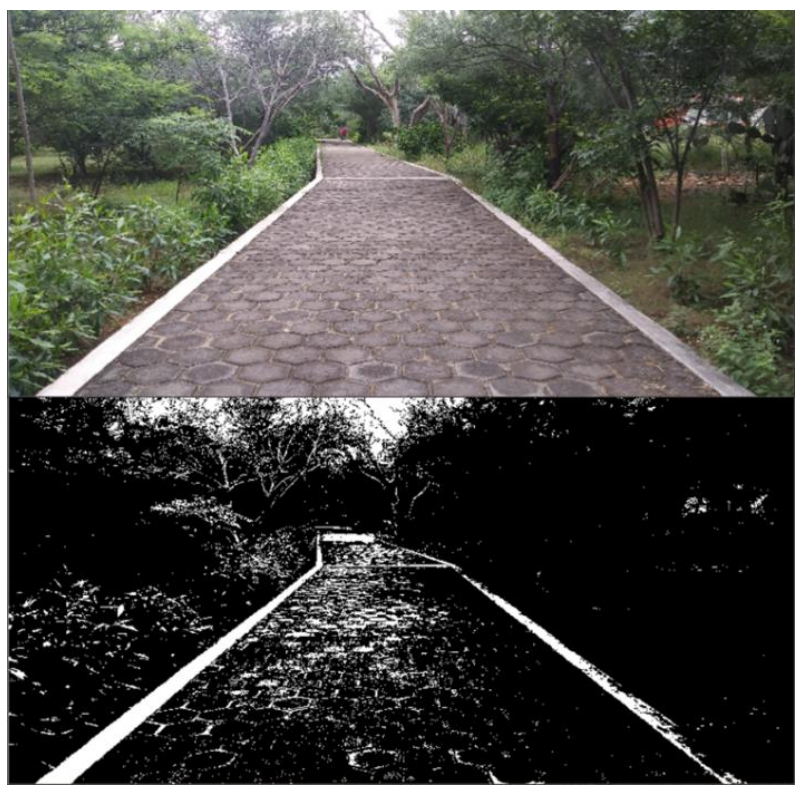

Figura 1 Aplicación del método de umbralización

\section{Suavizado de imagen}

En toda imagen hay una cierta cantidad de ruido debido al medio de transmisión de la señal. El ruido se manifiesta como píxeles aislados los cuales toman un nivel de gris diferente al de sus vecinos (Esqueda, 2002).

La aplicación de filtros de suavizado en una imagen tiene la finalidad de reducir el ruido dentro de esta. El ruido es el conjunto de detalles indeseables en una imagen. Como resultado una superficie de un objeto puede aparecer irregular y sus bordes mal definidos (Nuñez, 2008).

El filtro para eliminar el ruido en imágenes digitales se puede clasificar en tres tipos: Promediado, Mediano y Gaussiano. El filtro de promediado lleva al píxel central a aproximarse a las de sus vecinos, esto con el fin de que tenga una mayor resolución espacial ya que cada píxel retendrá algo más de sus características originales. El filtro mediano toma al píxel central al cual se le asigna el valor mediano de los píxeles de la máscara; contrario al promediado, este filtro tiene como fin eliminar la contribución de píxeles que contengan valores extremos, para obtener una imagen más homogénea con menor cantidad de detalles. El filtro Gaussiano es aquel que emborrona las imágenes y elimina el ruido. Después de aplicar la umbralización se utilizó el filtro mediano para eliminar el ruido de la imagen.

\section{Operaciones Morfológicas}

Las operaciones morfológicas tienen como objetivo simplificar los datos de una imagen, mantener las características esenciales y eliminar aspectos irrelevantes de dicha imagen.

Algunas de las funciones de estas operaciones son la supresión de ruido y simplificación de formas. De igual forma, estas funciones permiten destacar la estructura de un objeto, así como extraer el esqueleto, marcado de objetos, envolvente convexa, ampliación y reducción. Por último, hay funciones que permiten la descripción cualitativa de objetos, como el área, perímetro, diámetro, etc. (Tello, 2006).

Una de las funciones utilizadas dentro de las operaciones morfológicas es la función de apertura. Esta función consiste en la aplicación de la función de erosión en seguida de la función de dilatación para que de esta forma se puedan eliminar protuberancias finas y así suavizar los contornos de un objeto (Torres y Bello, 2002).

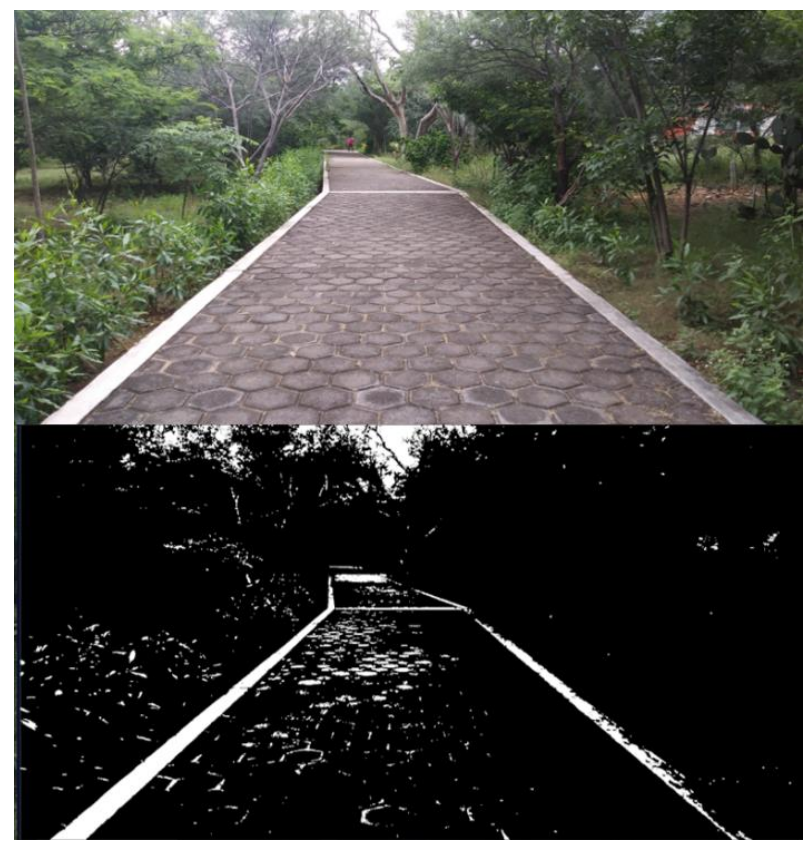

Figura 2 Operación morfológica de Apertura (Opening)

\section{Algoritmo de Hough}

Paul Hough (1972) elaboró un algoritmo de extracción de características llamado transformada de Hough. Esta técnica se utiliza para aislar características dentro de una imagen. La idea es encontrar curvas que puedan ser parametrizadas como líneas rectas, polígonos y círculos. 
Una ecuación conveniente para poder describir un conjunto de líneas es la notación paramétrica o normal $\rho=x \cos \theta+y \sin \theta$ en donde $\rho$ es la longitud de una normal desde el origen hasta la línea y $\theta$ es el ángulo de $\rho$ con respecto al eje x (Duque y Ospina, 2004). Cada valor $\mathrm{x}_{\mathrm{i}}, \mathrm{y}_{\mathrm{i}}$ se calcula usando la ecuación $\rho=$ $x_{i} \cos \theta+y_{i} \operatorname{sen} \theta \mathrm{y}$ los valores de $\operatorname{los}\left(\theta_{\mathrm{i}}, \rho_{\mathrm{i}}\right)$ se almacenan en un arreglo discreto acumulativo del espacio $(\theta, \rho)$. El valor de los parámetros de solución $\left(\theta \mid 0, \rho_{0}\right)$ son obtenidos de la celda discreta del espacio $(\theta, \rho)$ que tenga más valores acumulados. Los parámetros de solución de la línea recta obtenidos $(\theta, \rho)$, se convierten a la parametrización dada por la ecuación $A=a+$ $b X$ usando la relación entre las dos rectas perpendiculares (Paz y otros, 2006).

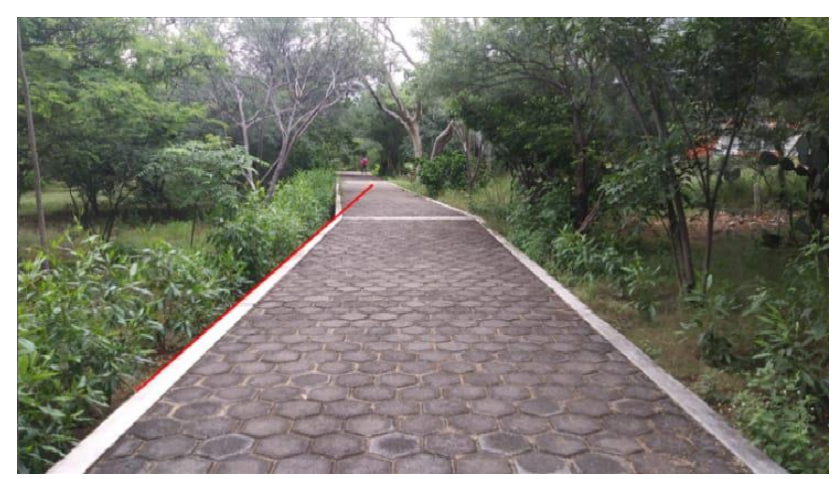

Figura 3 Ejemplo del Algoritmo de Hough

\section{Niveles de Autonomía}

Autonomía - "Un sistema no tripulado tiene la capacidad integrada de sentir, percibir, analizar, comunicar, planear, tomar decisiones y actuar para cumplir alguna tarea asignada" (Huang y otros 2007). El modelo de capacidad autónoma contextual para sistemas no tripulados es caracterizado por la misión que el sistema es capaz de realizar, el entorno en el que se realiza la misión, y la independencia humana que se permite para realizar la misión.

Cada uno de estos aspectos son atribuidos a un conjunto de métricas para la especificación, análisis, evaluación y medición de la capacidad autónoma contextual de un sistema no tripulado en particular. Este modelo de capacidad contextual facilita la caracterización de sistemas no tripulados desde las perspectivas de requerimientos, capacidades, niveles de dificultad, complejidad o sofisticación. De igual forma este modelo proporciona formas de caracterizar los modos de operación de sistemas no tripulados autónomos (Huang y otros, 2007).
Dentro de este trabajo se estima, en base al modelo de capacidad autónoma contextual, un nivel alto de independencia humana ya que el VANT navegará de forma autónoma por los pasillos de adoquín gris. La única ayuda que el VANT obtendrá será el encendido del VANT por parte del humano. Nivel medio en complejidad de la misión ya que el VANT tiene que identificar el pasillo con la ayuda de procesamiento digital de imágenes. Nivel medio en complejidad de entorno, ya que la variación viento, luz y sombras son inestables en aire libre.

\section{Metodología}

El objetivo de este trabajo es diseñar e implementar un algoritmo que permita a un vehículo aéreo no tripulado (VANT) recorrer de forma autónoma 30 metros en línea recta sobre pasillos de adoquín gris a una altura máxima de $1 \mathrm{~m}$ y a una velocidad de $0.5 \mathrm{~m} / \mathrm{s}$ utilizando la cámara integrada del VANT.

Las pruebas se realizaron con un cuadrirotor de modelo Parrot Bebop 2 el cual es de uso convencional y que además cuenta con una librería SDK compatible con Linux, Windows, iOS y Android para el desarrollo de la aplicación en $\mathrm{C}$ y Python. Se utilizó un teléfono celular de modelo LG k20 plus para poder controlar el cuadrirotor con la finalidad de que este tenga mayor alcance de recorrido sobre los pasillos. Una vez teniendo el smartphone y el VANT a la mano, se prosiguió a diseñar un algoritmo capaz de reconocer los pasillos de la Universidad.

\section{Diseño del algoritmo}

Para el diseño del algoritmo se hicieron diversas pruebas con los métodos y algoritmos recopilados para estar seguro de que estos fueran útiles en la detección de los pasillos de adoquín gris. En la siguiente imagen se muestra el flujo del procesamiento digital para la detección de los pasillos. 


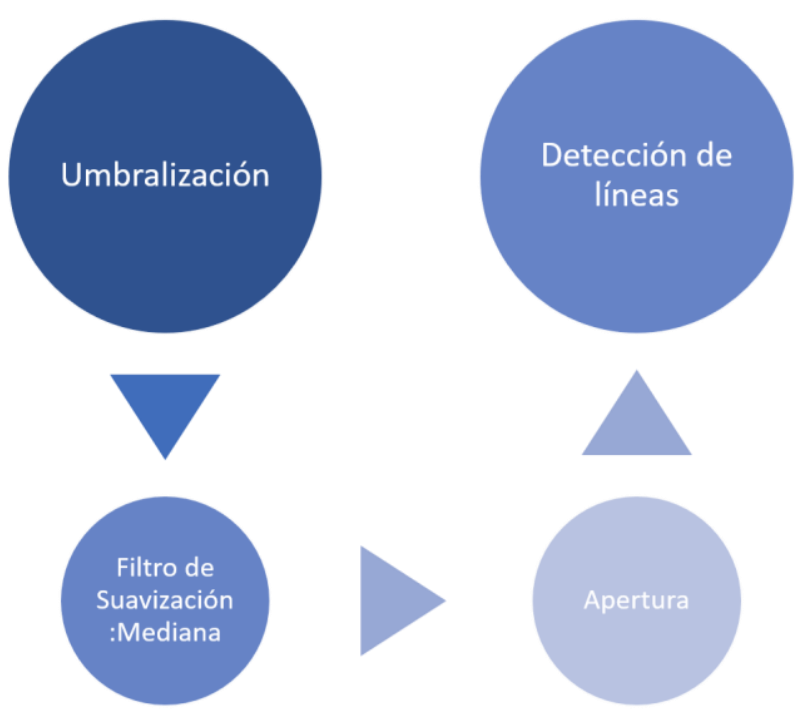

Figura 4 Flujo del procesamiento digital para la detección de los pasillos de adoquín

Para empezar a aplicar los filtros, la imagen que se tomará por medio del VANT se transformará a una escala de grises por el motivo de que algunos de estos filtros requieren de esta conversión en imágenes RGB.

Una vez teniendo la imagen en escala de grises se hacen dos recortes de la imagen. Se toma el lado izquierdo y el lado derecho de la imagen para poder evaluarlas individualmente, ya que es necesario poder identificar el borde de los pasillos.

\section{Umbralización}

Para detectar los bordes de los pasillos de adoquín gris dentro de la imagen se tuvo que establecer un valor especifico el cual define el umbral. Para poder definir este valor se calculó el valor que permitiera distinguir las orillas de los pasillos. Los contornos de concreto que sostienen a los adoquines juntos, a lo largo del camino, tienen una tonalidad muy específica, ya sea que haya o no una variación en la iluminación.

Se hicieron pruebas con la umbralización para detectar estos contornos. Como resultado de estas pruebas el valor que nos mostró mejores resultados con respecto a la detección de estos contornos fue de 170, por lo que podemos detectar dos líneas paralelas verticales dentro de la imagen que se aprecian después de la umbralización.

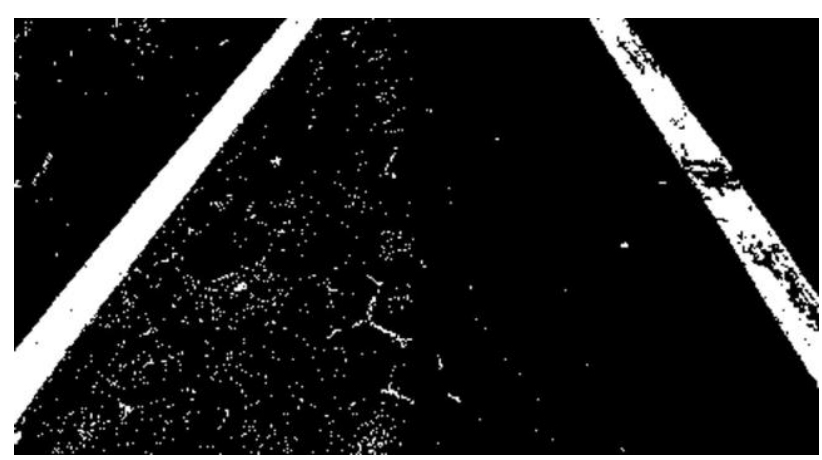

Figura 5 Imagen de los bordes de los pasillos con el filtro de umbralización

\section{Filtro de Suavización: Mediana}

Una vez que se obtuvo el resultado de la umbralización, se le aplicó un filtro de suavizado para eliminar ruido de la imagen. Se decidió aplicar un filtro a la imagen para poder definir los bordes dentro de la imagen y distinguirlas de otras formas que se encuentran dentro de ella.

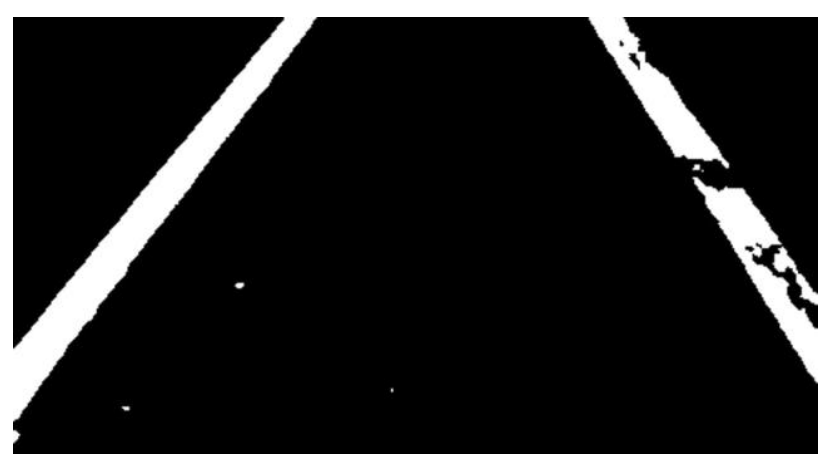

Figura 6 Imágenes de los bordes de los pasillos con filtro de suavización

\section{Apertura}

Una vez terminado el proceso de suavización, al resultado se le aplico la operación morfológica de apertura. Esto para poder eliminar el poco ruido que haya quedado y simplificar las formas que existen dentro de la imagen.

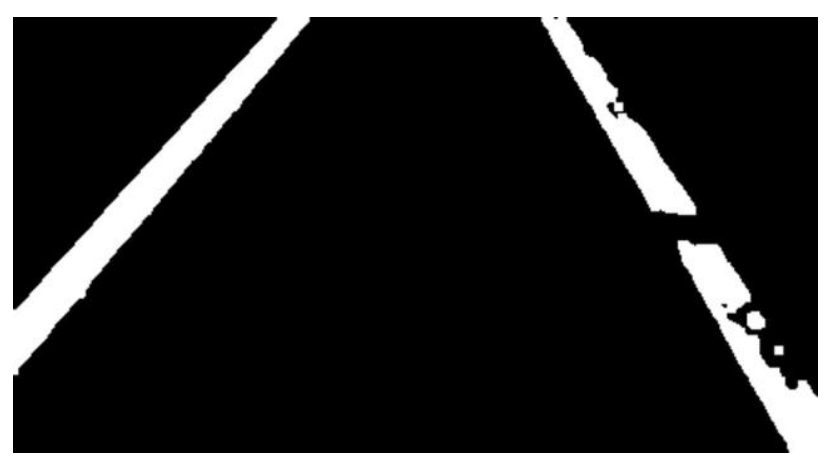

Figura 7 Imágenes de los bordes de los pasillos con la operación morfológica de apertura 


\section{Detección de líneas}

Como último paso del proceso, al resultado final, se le aplicó la detección de líneas de Hough para detectar si hay líneas rectas dentro de la imagen. El número mínimo de líneas a detectar se estableció en un valor de 200. Esto para no detectar líneas que tal vez no sean exactamente los bordes que sostienen a los adoquines dentro de los pasillos.

\section{Detección de puntos de referencia}

El punto de referencia para indicar el aterrizaje es una hoja de papel cascarón dentro del camino. Se diseño una función que permite identificar la forma de la hoja con la cual se le estará indicando al VANT que es un punto de llegada y tendrá que aterrizar. Esta función recorta una zona de interés en donde se busca la figura de un rectángulo con un parámetro de tonalidad para poder buscar solo los objetos de color blanco.

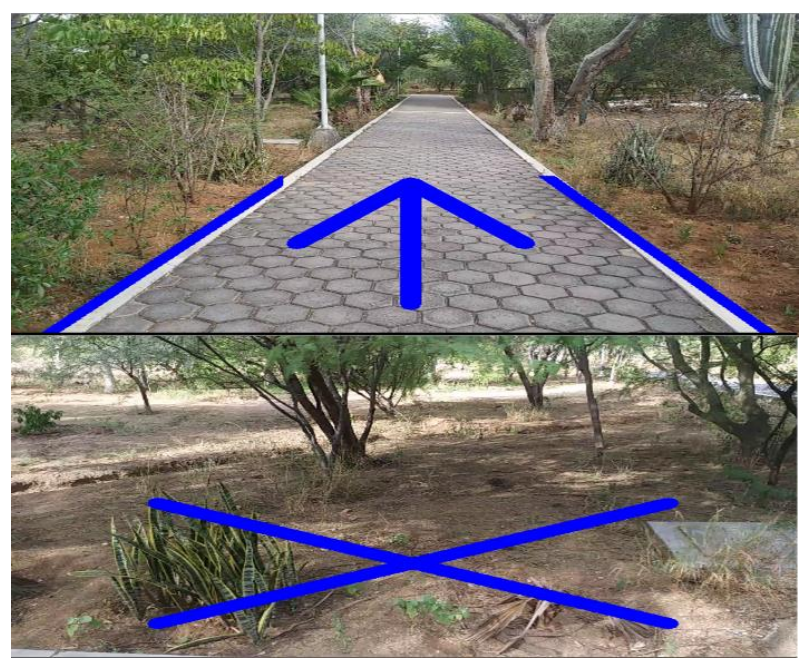

Figura 8 Detección de cuando hay y no hay camino dentro del pasillo de adoquín

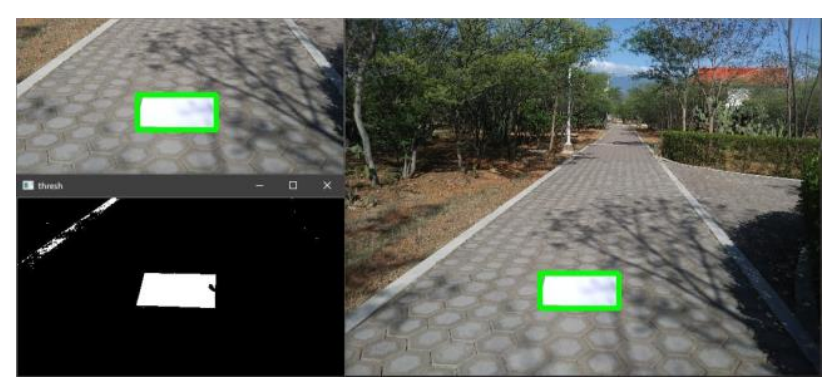

Figura 9 Hoja de papel cascaron la cual indica que es un punto de llegada dentro del camino

\section{Pruebas y resultados}

Las pruebas consistieron en recorrer $30 \mathrm{~m}$ en línea recta sobre los pasillos de adoquín gris sin obstáculos. Con luz de día en un horario de 9 a 10 am de la mañana sin vientos no mayores a $20 \mathrm{~km} / \mathrm{h}$. Para hacer las pruebas con el VANT y el algoritmo se eligió el pasillo que conecta el Instituto de Farmacobiología con el entronque que conecta a la Biblioteca, Servicios Escolares y las Aulas de la Universidad.

En las primeras pruebas con el VANT, se le añadió el dispositivo móvil al VANT en la parte superior como se muestra en la Figura 10, esto para comprobar si el VANT era capaz de soportar el peso del dispositivo ya que el VANT es un modelo comercial. Los resultados de estas pruebas fueron negativos ya que el VANT al tener peso extra se desestabiliza al momento de despagar y mantenerse en algún punto fijo. Debido a este resultado, se hicieron otra serie de pruebas en las cuales se optó por quitar el dispositivo móvil del VANT.

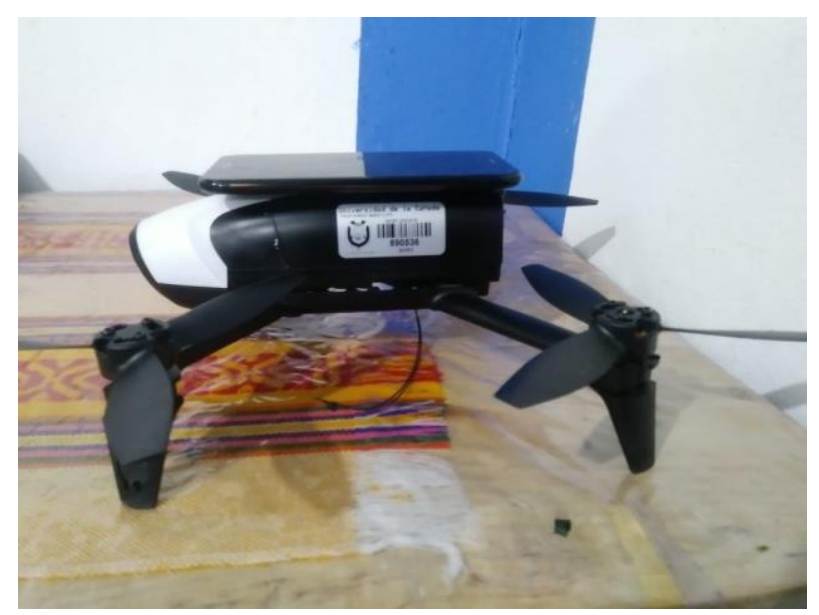

Figura 10 Dispositivo móvil sobre el VANT

Dentro de las primeras pruebas, el VANT inicia el vuelo correctamente, pero se dilataba en reconocer los pasillos de 3 a 5 segundos antes de poder avanzar. Esto debido a que al iniciar el despegue las imágenes captadas son borrosas y están fuera de los parámetros para reconocer los pasillos. Una vez que el VANT se estabilizaba en el aire, se iniciaba el proceso de reconocimiento de los pasillos.

Si se reconocía el pasillo y detectaba que hay paso, este avanzaba hacia delante hasta que encontrara algún punto de llegada o que simplemente ya no hubiera paso dentro del camino. 
Se puede considerar a las divisiones de concreto (Figura 11) que separan por bloques a los adoquines dentro de todos los pasillos de la universidad como un obstáculo, debido a que al llegar a las divisiones de concreto el VANT disminuía su velocidad para analizar cuidadosamente los bordes de los pasillos y verificar que sea continuación del pasillo y no algún área donde no hubiera paso. Este proceso le tomaba de 10 a 15 segundos para avanzar lentamente y seguir con el recorrido.

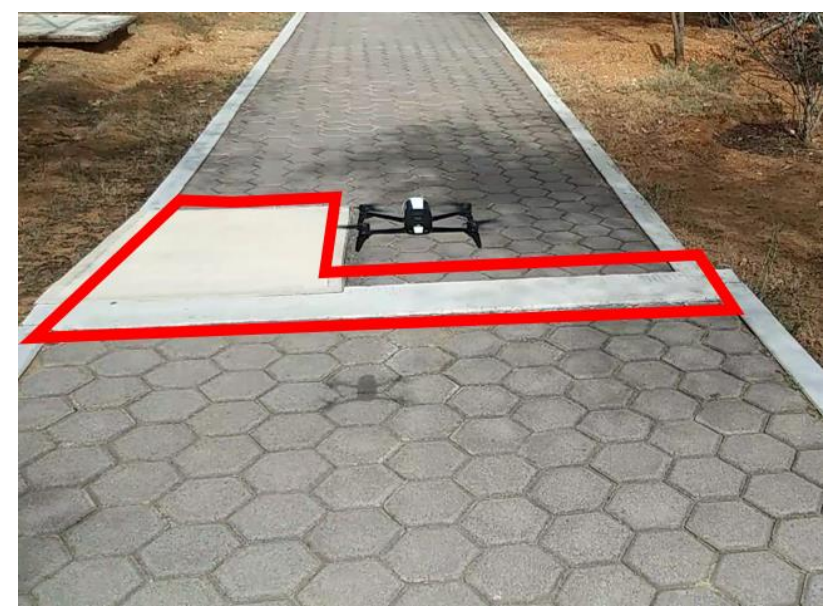

Figura 11 Separación de concreto

$\mathrm{Al}$ momento de que el VANT localizaba algún punto de llegada, el VANT aterrizaba inmediatamente enfrente del punto de llegada, que en este caso es el papel cascarón. El proceso para detectar el papel cascarón en los pasillos se realizó por medio del reconocimiento de figuras geométricas y su color, que en este caso es un rectángulo blanco.

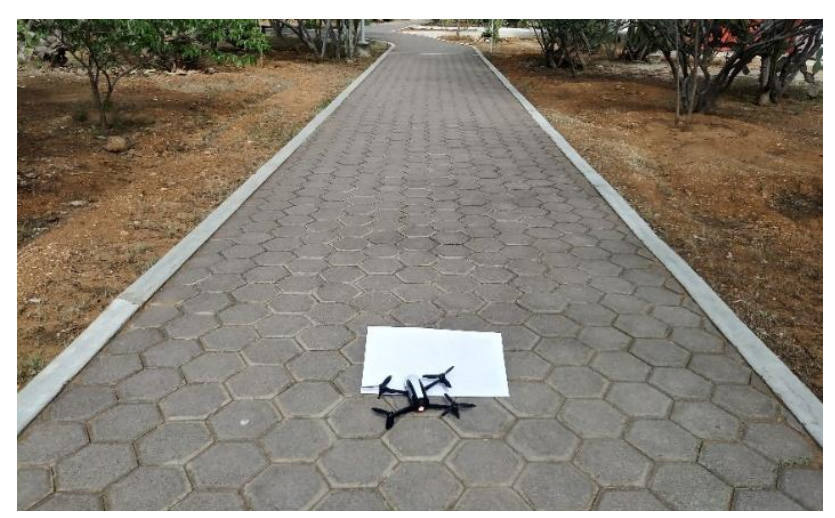

Figura 12 Punto de llegada (punto de referencia)

Se tomaron los 10 mejores resultados obtenidos de las pruebas que se hicieron dentro de los pasillos.

\begin{tabular}{|l|l|r|}
\hline $\mathbf{N}^{\circ}$ de prueba & \multicolumn{1}{c|}{ Completo } & Tiempo(minutos) \\
\hline 1 & $\mathrm{Si}$ & $1: 05$ \\
\hline 2 & $\mathrm{Si}$ & $0: 49$ \\
\hline 3 & $\mathrm{Si}$ & $1: 09$ \\
\hline 4 & $\mathrm{Si}$ & $1: 15$ \\
\hline 5 & $\mathrm{Si}$ & $0: 58$ \\
\hline 6 & $\mathrm{Si}$ & $0: 48$ \\
\hline 7 & $\mathrm{Si}$ & $1: 09$ \\
\hline 8 & $\mathrm{Si}$ & $0: 54$ \\
\hline 9 & $\mathrm{Si}$ & $1: 01$ \\
\hline 10 & $\mathrm{Si}$ & $1: 05$ \\
\hline Promedio de Tiempo & $\mathbf{1 : 0 1}$ \\
\hline
\end{tabular}

Tabla 1 Resultados de pruebas de vuelo exitosas

\section{Conclusiones}

El VANT logró reconocer y recorrer los pasillos de la Universidad de forma autónoma eficazmente. Todo esto se logró hacer a través del procesamiento digital de imágenes, las cuales fueron captadas por medio de la cámara integrada del VANT. Las imágenes obtenidas por el VANT se mandaban a través de una conexión Wifi que se hizo entre el VANT y el celular. Dentro del celular se instaló una aplicación la cual se programó con el lenguaje Java y la librería Parrot Bebop SDK. Dicha aplicación realizó el procesamiento de imágenes digitales, así como también le indicó al VANT los comandos de vuelo dependiendo del resultado de las imágenes analizadas.

\section{Referencias}

Araujo-Fernandeza, E. y García-González, R. J. (2013). Desarrollo del sistema de navegación autónoma para el "UAV 1" de la escuela naval de cadetes Almirante Padilla. Revista Derrotero, 7(2013), pp. 87-98.

Engel, J. J. (2011). Autonomous Camera-Based Navigation of a Quadrocopter (Tesis de maestria). Technical University of Munich, Munich, Alemania.

Fuentes-Brea, J. P. (2013). Arquitectura cognitiva híbrida para la navegación autónoma de UAVs mediante mapas topológicos visuales (Tesis de doctorado). Universidad Politécnica de Madrid, Madrid, España.

Guevara-Soriano, F., Reyes-Montero, A. A., Sánchez-López, A. (2017). Seguimiento autónomo de personas con un robot aéreo no tripulado. Research in Computing Science, 135(2017), pp. 71-84. 
Martínez-Carranza, J., Valentín, L., MárquezAquino, F., González-Islas, J. C., y Loewen, N. (2016). Research in Computing Science, 114 (2016), pp. 111-124.

Munguía, R., Cabrera, A., Rojas, O., y Martínez-Carranza, J. (2016). Combinación de un controlador PID y el sistema Vicon para micro-vehículos aéreos. Research in Computing Science, 114(2016), pp. 161-172.

Navas-Flores, D. F. y Vargas-Suasnavas, J. R. (2018). Diseño e implementación de un prototipo de detección y localización de obstáculos a través de reconstrucción tridimensional mediante el uso de una cámara estereoscópica (Tesis de pregrado). Escuela Politécnica Nacional, Quito, Ecuador.

Plaza-Rey, D. (2017). Navegación autónoma de drones y automatización de rutas aplicadas a la limpieza de edificios (Tesis de pregrado). Universidad Politécnica de Cataluña, Barcelona, España.

Riveros-Guevara, A., Salas-López, C. N. y Solaque-Guzmán, L. (2012). Aproximación a la navegación autónoma de una plataforma móvil, mediante visión estereoscópica artificial. Ciencia e Ingeniería Neogranadina, 22(2), pp. 111-129.

Schiaffino, M. P. (2006). Navegación autónoma basada en visión estereoscópica y lógica difusa (Tesis de pregrado). Universidad Nacional de Lujan, Buenos Aires, Argentina.

Viñals-Pons, J. (2012). Localización y generación de mapas del entorno (SLAM) de un robot por medio de una Kinect (Tesis de pregrado). Universidad Politécnica de Valencia, Valencia, España. 